\title{
Comparison of the Knowledge and Performance of Surgical Technicians and Technologists Regarding the Observance of the Aseptic Technique
}

\author{
Negin Larti ${ }^{1}$, Mozhgan Jokar ${ }^{2}$, Fatemeh Maraki ${ }^{3}$, Akram Aarabi $^{4}$, Mohammad Reza Zarei $^{5}$
}

\begin{abstract}
Background \& Aims: Many of the risks in the operating room are related to surgery and most of them are preventable. One of the risks is site infection, which occurs within 30 days or a year after surgery. Infection at the site of the surgery may cause problems such as increased postoperative mortality, delayed recovery, increased length of hospital stay, and increased treatment costs. It is important to follow aseptic techniques in the operating room to prevent infection. All members of the surgical team must be committed to ensuring that the surgical environment is sterile. The knowledge and practice of the operating room associates and specialists play an important role in its proper implementation. Using their knowledge and practice, members of the surgical team can actively reduce the side effects of violations in the aseptic technique. Knowing the level of knowledge and performance of staff can be a way to show their weaknesses and training needs, and also according to the research that compares the knowledge and performance of professionals and operating room specialists. The study was designed to compare the knowledge and practice of operating room associates and specialists regarding the observance of aseptic technique.

Materails \& Methods: This cross-sectional study was performed on 235 operating room associates and specialists in eight teaching and medical hospitals in Isfahan in 2017-1997. Inclusion criteria were having a BA or Bsc degree in the operating room and having at least six months of experience in the operating room to become familiar with the principles and rules of this department. Exclusion criteria included withdrawal from the study, incomplete response to questionnaires. There was reluctance to continue cooperation in the research process. Sampling was done by the random stratified method. The research tools included a demographic information form (age, sex, work experience, degree, and name of the hospital understudy), a researcher-made questionnaire to measure knowledge (completed by the samples), and a researcher-made checklist to measure the performance of the samples in terms of compliance. It was an aseptic technique (completed by the researcher). After obtaining written satisfaction from individuals and emphasizing the lack of effect of grades on job evaluations, the researcher provided a knowledge assessment questionnaire to individuals. Then, the performance questionnaire of each person was completed by the researcher by observing three surgeries in which the person had the role of a scrub (washed hand). In this study, an attempt was made to observe the performance of the samples during three identical surgeries as much as possible. To reduce the effect of sample performance on the researcher's presence in the environment, the person who obtained written consent from the samples was not the same as the person who observed the sample performance. Data analysis was performed with descriptive and analytical statistics in SPSS software version 22 .
\end{abstract}

1. MS in Operating Room, Department of Operating Room, School of Paramedical Sciences, Kermanshah University of Medical Sciences, Kermanshah, Iran

2. MS in Medical Surgical Nursing, Department of Operating Room, School of Nursing and Midwifery, Isfahan University of Medical Sciences, Isfahan, Iran

3. MS in Operating Room, Department of Operating Room, Borojen School of Nursing, Shahrekord University of Medical Sciences, Shahrekord, Iran

${ }^{4}$. Assistant Professor, Nursing and Midwifery Care Research Center, School of Nursing and Midwifery, Isfahan University of Medical Sciences, Isfahan, Iran

5. MS in Operating Room, Student Research Committee, School of Nursing and Midwifery, Isfahan University of Medical Sciences, Isfahan, Iran (Corresponding author) Tel: +98-9137375832 mohammad.zarei3113@gmail.com 
Results: Out of 235 participants, 10 were excluded from the study due to incomplete responses to the questionnaires and five due to withdrawal from the study. Regarding the demographic characteristics of the two groups, the mean age and work experience of the associates were significantly higher than the specialists. Also, the frequency distribution for gender was significantly different between the two groups. The knowledge score of operating room associates and specialists were at a good level and their performance score was average. The mean score of knowledge $(\mathrm{P}=0.047)$ and performance $(\mathrm{P}=0.01)$ of specialists was significantly higher than associates. In both associates $(\mathrm{P}=0.027)$ and specialists $(\mathrm{P}=0.032)$, there was a direct relationship between knowledge and performance scores regarding the aseptic technique. In neither group, there was a significant relationship between knowledge and performance scores regarding aseptic technique with age and work experience and between knowledge and performance scores with gender.

Conclusion: The results showed that the score of knowledge of operating room associates and specialists regarding aseptic technique was at a good level, however, their performance score was average. In crowded medical centers such as the main medical centers in Isfahan, staff does not have enough time to use properly trained aseptic techniques, which can affect the quality of care in the operating room. One of the possible reasons for the gap between knowledge and performance scores in individuals can be the distance between theoretical lessons learned in the classroom and performance in the clinic. The results of comparing the scores of associates and operating room experts regarding the aseptic technique showed that the average score of knowledge and practice of operating room specialists was significantly higher than associates. Due to this, it can be considered as increasing knowledge along with increasing skills and performance. In the present study, there was a direct relationship between knowledge score and performance. So that with the increase of knowledge score, performance score also improved in two groups. Increasing the knowledge of operating room associates and specialists about aseptic techniques can improve their performance. Infection at the surgical site is one of the most common postoperative complications and an aseptic technique can be one of the ways to prevent it. Therefore, measures such as continuous training, holding workshops, and continuous monitoring of knowledge and performance of employees, have an effective role in improving their performance. Therefore, it is hoped that the findings of this study will lead to more accurate monitoring of the performance of health care providers to synchronize their knowledge and performance with each other. Also, due to the higher score of knowledge and performance of operating room specialists, it is better to encourage professionals to continue their education. Besides, to improve the performance of operating room staff, the implementation of effective training programs should be considered.

Keywords: Knowledge, Practice, Nurse, Operating Room, Infection

\section{Conflict of Interest: No}

How to Cite: Larti N, Jokar M, Maraki F, Aarabi A, Zarei MR. Comparison of the Knowledge and Performance of Surgical Technicians and Technologists Regarding the Observance of the Aseptic Technique. Iran Journal of Nursing. 2019; 32(118):1-11.

Received: 2 March 2019

Accepted: 2 Jun 2019 


\title{
مقايسه دانش و عملكرد كاردانها و كار شناسان اتاق عمل درخصوص رعايت تكنيك آسيتيك
}

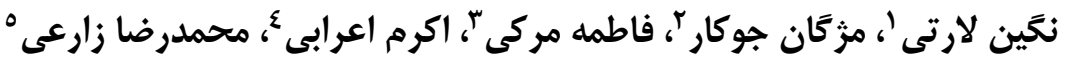

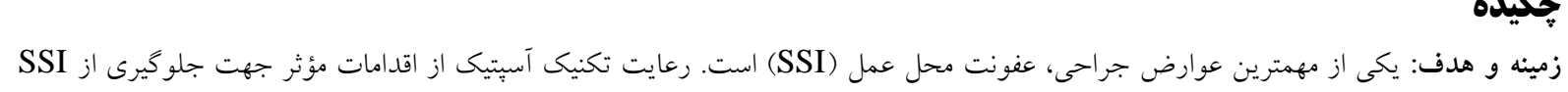

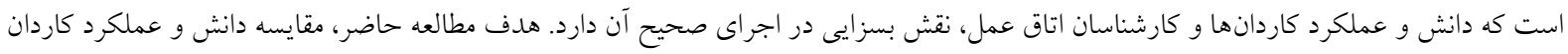

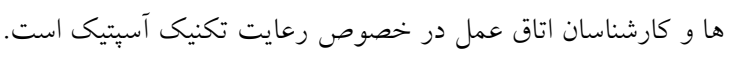

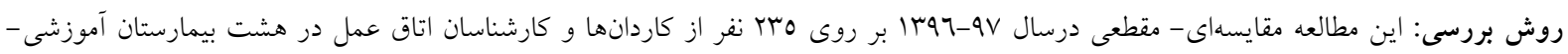

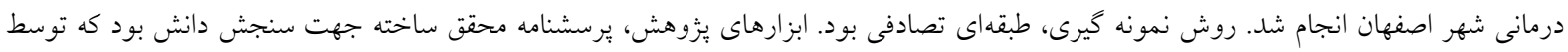

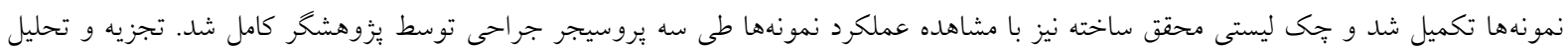

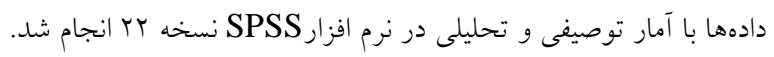

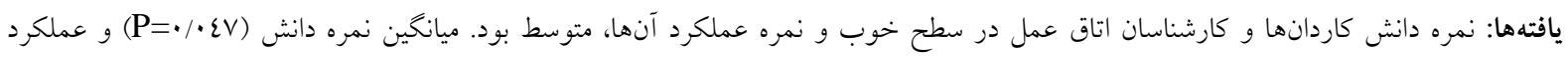

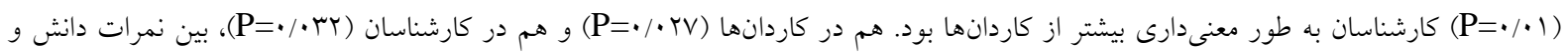
عملكرد رابطه مستقيم وجود داشت.

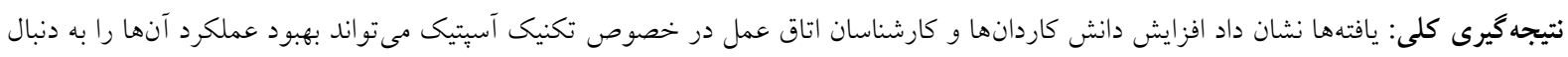

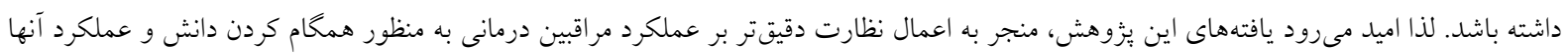

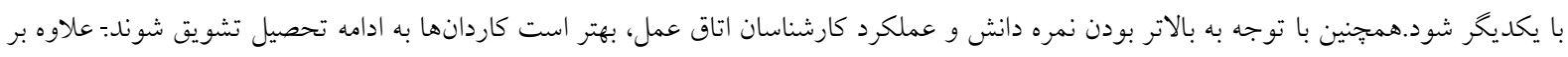

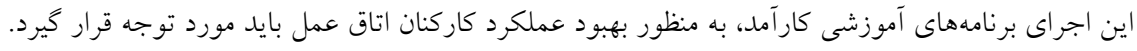

كليد وازهها: دانش، عملكرد، برستار، اتاق عمل، عفونت

تعارض منافع: ندارد

تاريخ دريافت: SV/MT/I

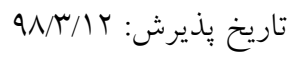

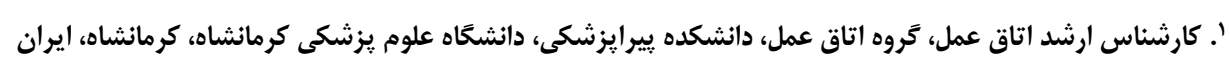

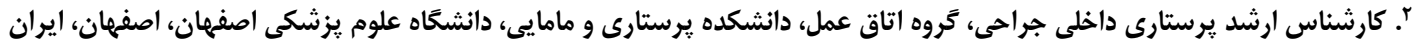

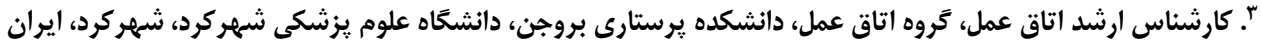

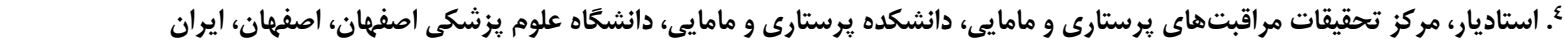

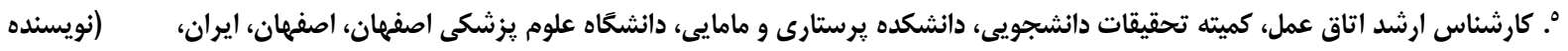


جراحى بايد نسبت به تضمين استريليتى استريل بودن

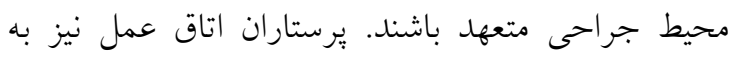

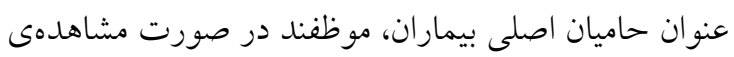

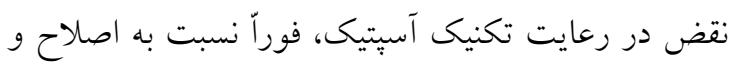

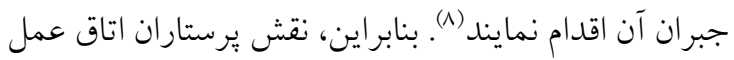

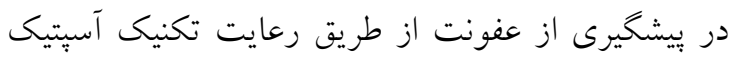

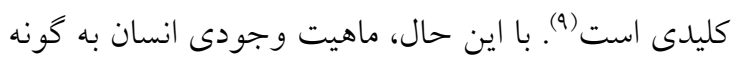

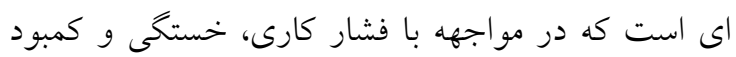
دانش، اصول اساسى و مهم را فراموش مى كند يا زمانى كه استه

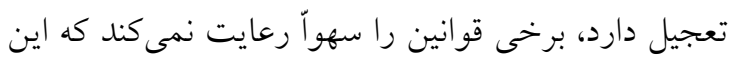
امر مىتواند بيماران را در معرض خطر ابتلا به عفونت و

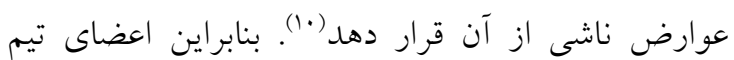

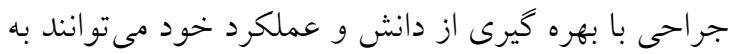
طور فعالى سبب كاهش عوارض جانبى ناشى از نقض در لراني

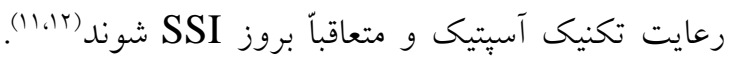
نتايج مطالعه Labrague و همكاران نشان داد كه هر قدر دانش يرستاران در خصوص رعايت تكنيك آسيتيك ارتقاء

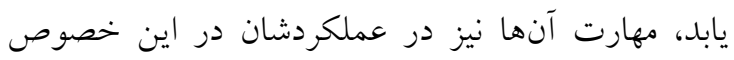

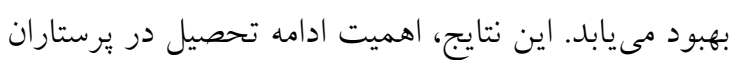

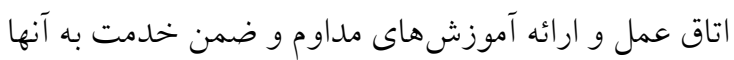

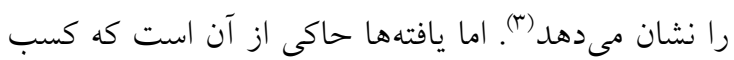
دانش و آكَاهى به تنهايى كافى نيست، بلكه نكته مهم تبديل

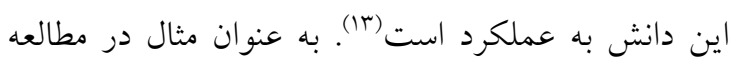

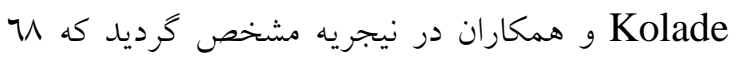
درصد يرستاران درباره اين كه انتقال عفونت از طريق مراقبين درمانى كه دستهاى خود را شستشو نمىدهند

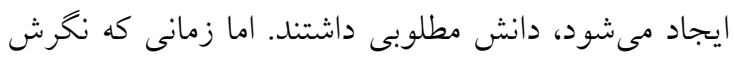

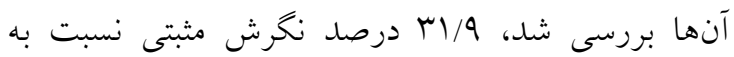
شستشوى مرتب و صحيح دستها داشتند و نكته قابل توجه اين كه با بررسى عملكرد اين افراد مشخص شد كه

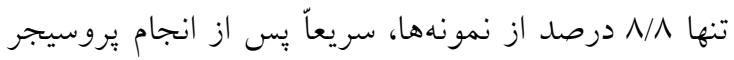

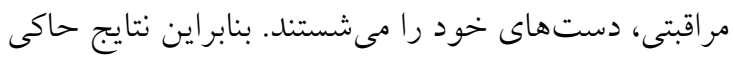

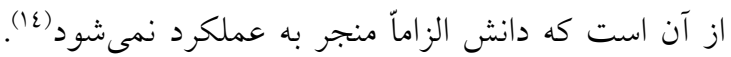

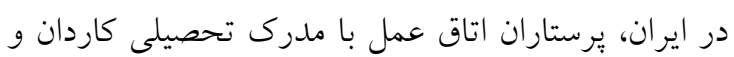

\section{مقدمه}

اتاق عمل، محيطى منحصر به فرد براى انجام درمانهاى

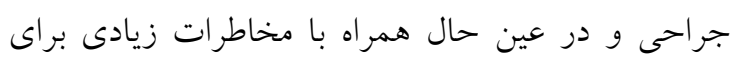

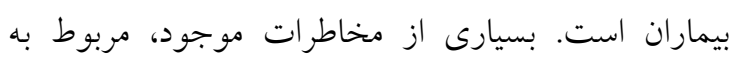

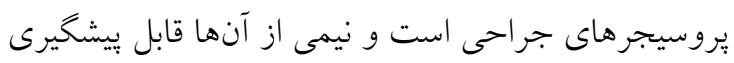

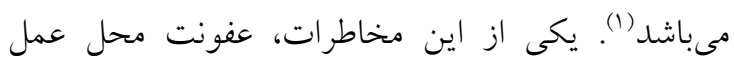
(Surgical Site Infection: SSI)

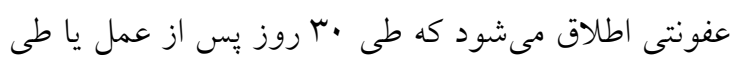

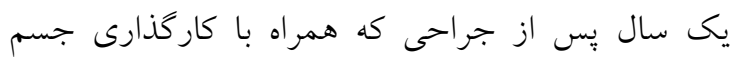

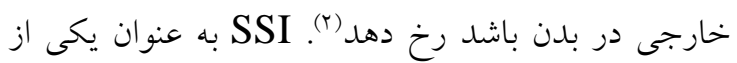

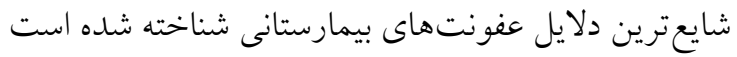

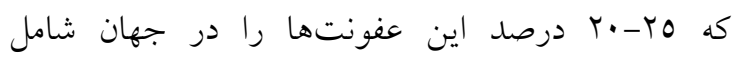

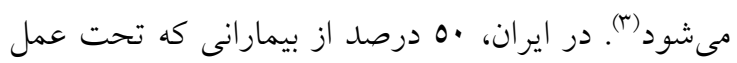

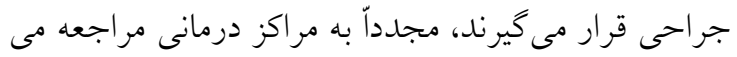
كنند كه از اين ميزان، بr درصد به علت عفونتهاى

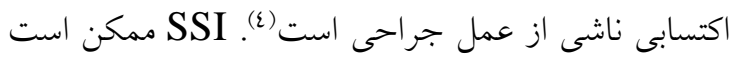

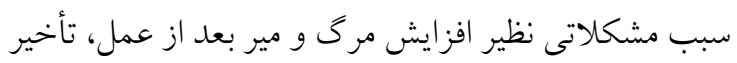

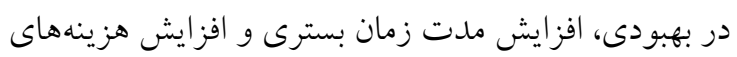

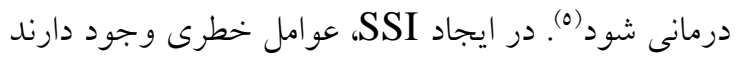

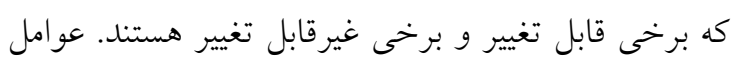

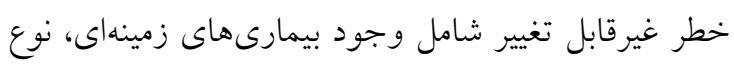

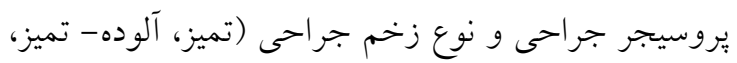

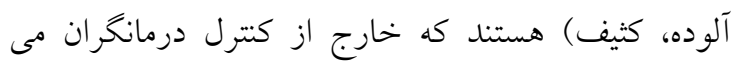

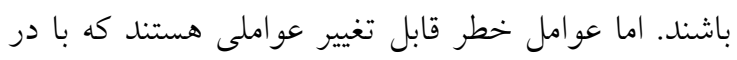

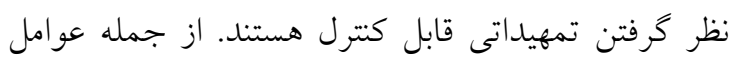

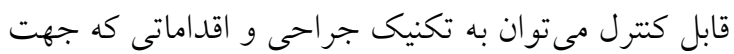

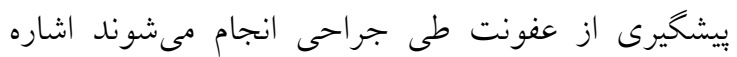

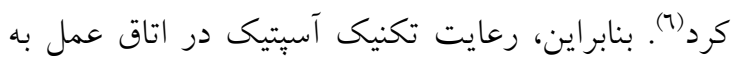

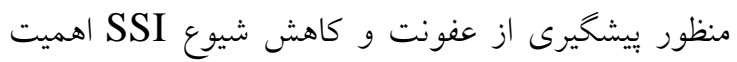

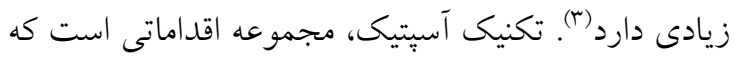
تحت شرايط بسيار كنترل شده با هدف كاهش آلودئى داردي

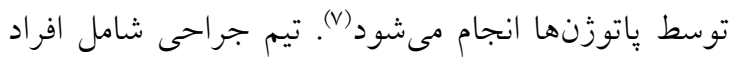
حرفهاى مختلفى جون جراحان، متخصصين و تكنسينهاى

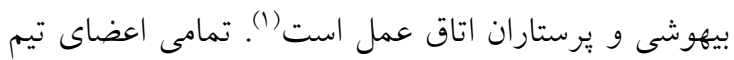


روش نمونه گيرى در اين ثئوهش به صورت طبقهاى تصادفى بود. بدين معنى كه هر يكى از هشت بيمارستان

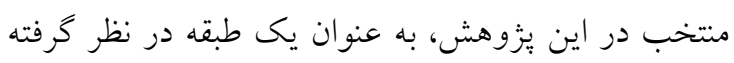

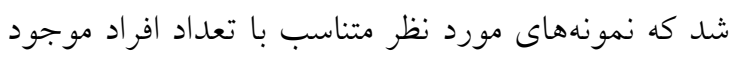

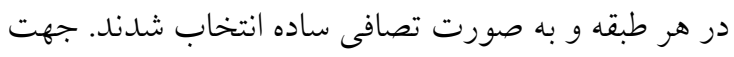

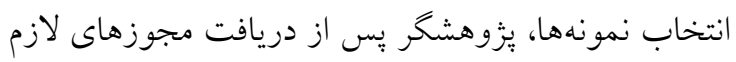

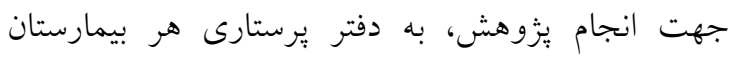

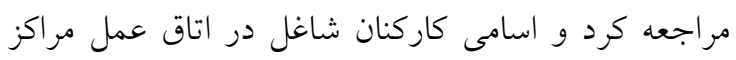

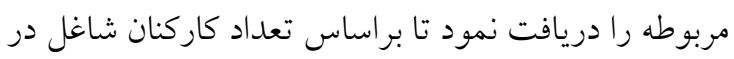
اتاق عمل هر مركز و بر اساس دارا بودن معيارهاى ورود،

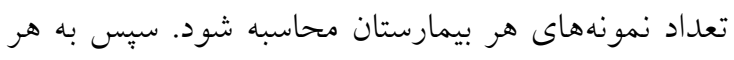
يكى از افراد شمارهاى اختصاص داده شد و نمونهها به بهان

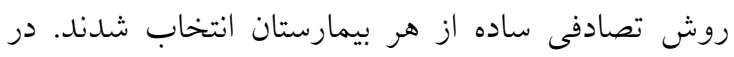

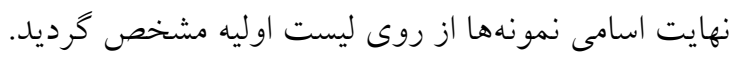

ابزار مورد استفاده در اين يزوهش حاوى سه بخش بود:

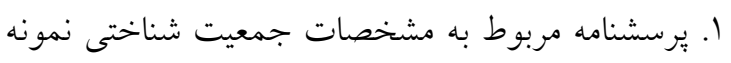
ها شامل: سن، جنس، سابقه كار، مدرى تحصيلى و نام

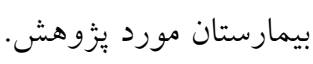
r. ابزار مورد استفاده جهت سنجش دانش كاردانها و و برون

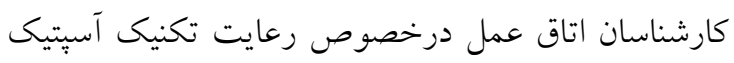

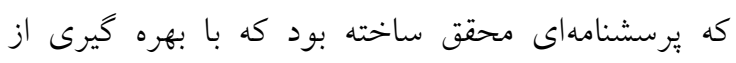

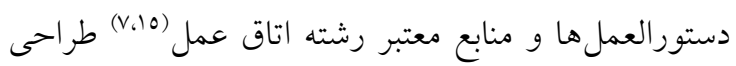

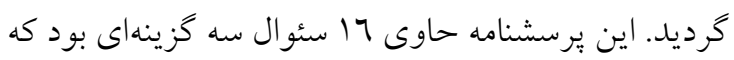
يك كزينه صحيح و دو ززينه غلط داشت. يرسشنامه

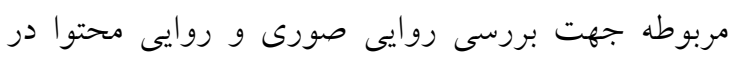

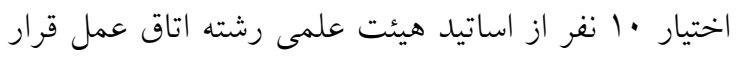

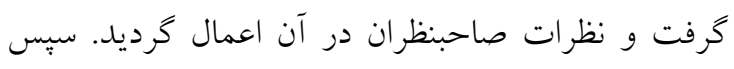

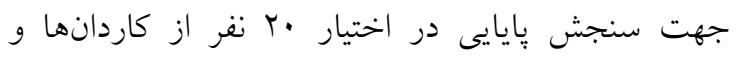
كارشناسان اتاق عمل كه جزو نمونهاى يثزوهش نبودند

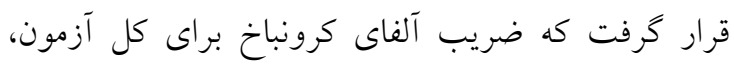

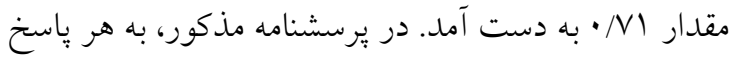
درست نمره 1 و به هر پاسخ نادرست نمره صفر تعلق

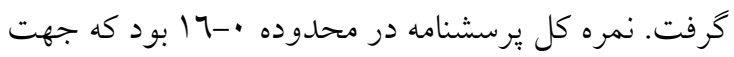

كارشناس در اتاق عمل مشغول به كار هستند و با توجه به

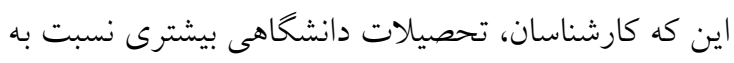

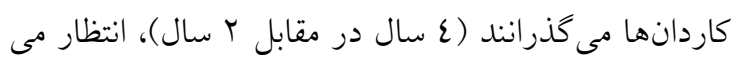

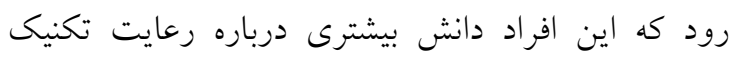

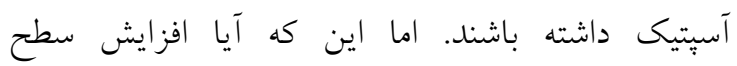
تحصيلات، الزاماً عملكرد كارشناسان را نسبت به كاردانها

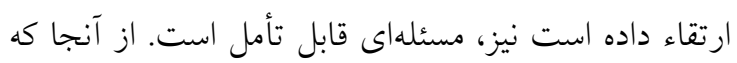

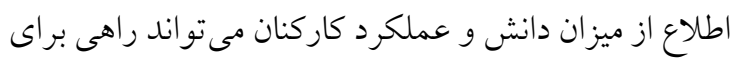

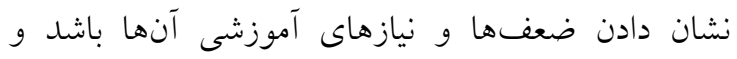
همجنين نظر به اين كه بر اساس جستجوهاى انجام شده

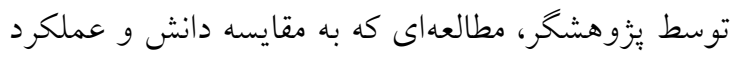
كاردانها و كارشناسان اتاق عمل در خصوص رعايت

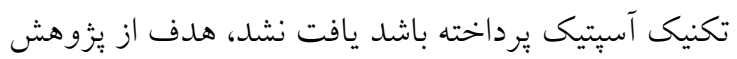

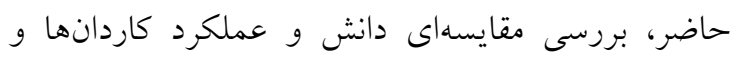

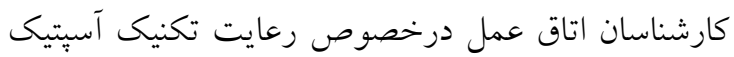
در اتاق عمل بيمارستانهاى متتخب وابسته به دانشخاه علوم

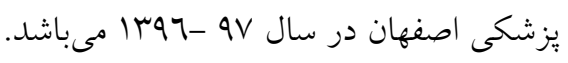

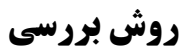

يزوهش حاضر يك مطالعه مقايسهاى - مقطعى مىباشد كه وروسي

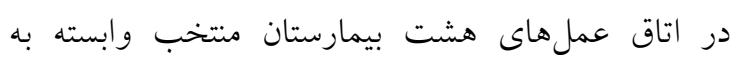

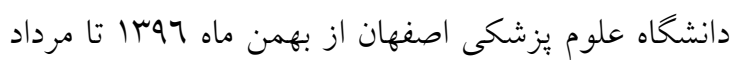

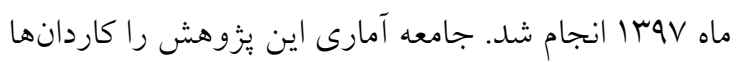
و كارشناسان اتاق عمل تشكيل دادند كه با در نظر كرفتن

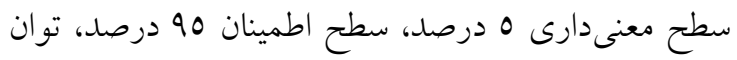

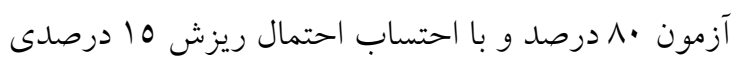

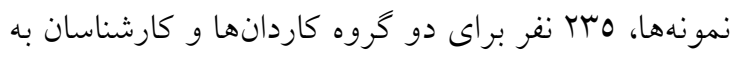

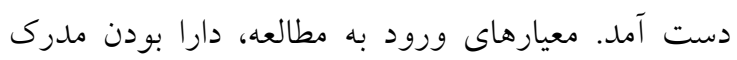
كاردانى يا كارشناسى در رشته اتاق عمل و داشتن حداقل

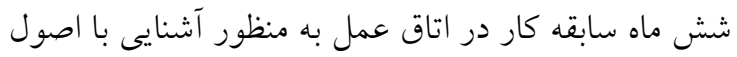

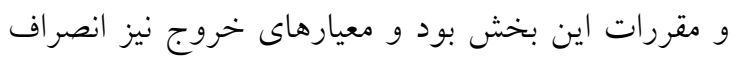

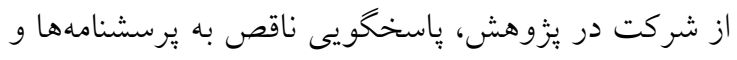

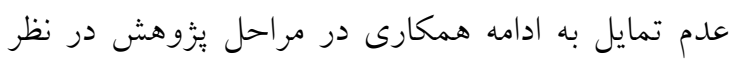
كرفته شد. 


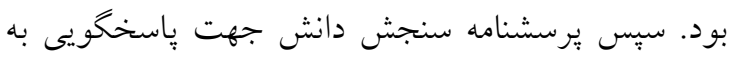

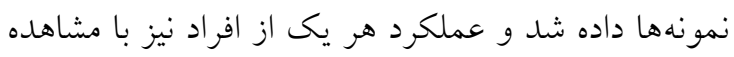

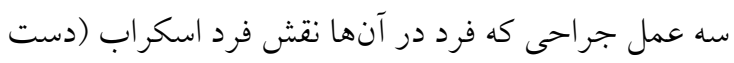

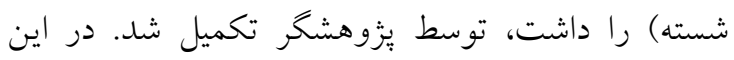

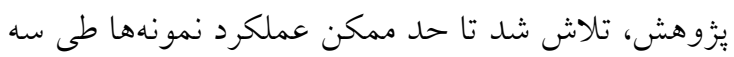
عمل جراحى يكسان مشاهده شود. علت مشاهده عملكرد طى سه بروسيجر جر احى اين بود كه اخر نمونه ها يك بار

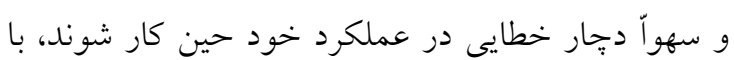

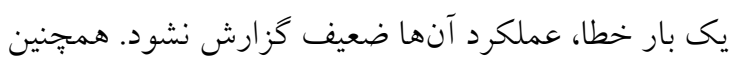

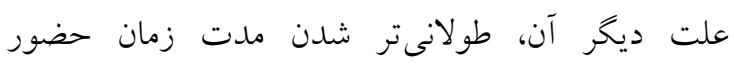
يزوهشخر در محيط يزوهش بود تا بدين ترتيب، حضور

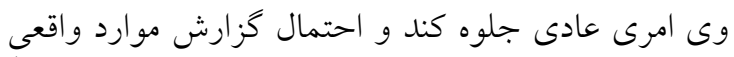
عملكرد، افزايش يابد. لازم به ذكر است كه جهت جلو گيرى از تحت تأثير قرار گرفتن نمرات عملكرد نمونه

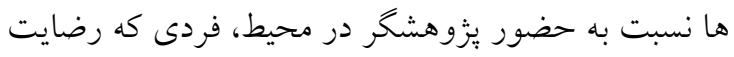

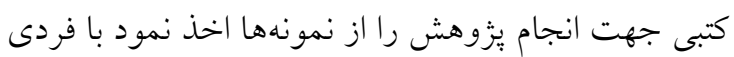
كه عملكرد نمونهها را مشاهده كرد، يكسان نبود. تجزيه و تحليل دادهها با استفاده از آمار توصيفى (ميانكين و فراوانى) و آزمونهاى آمارى t مستقل، مجذور كاى، آناليز

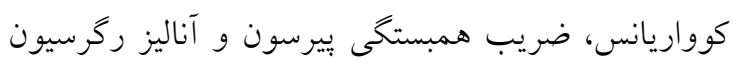

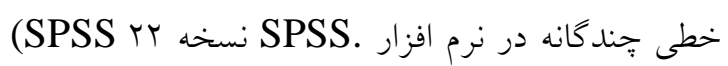
از P> Inc., Chicago, IL, USA) نظر آمارى، معنى دار در نظر گرفته شد.

\section{كافتهها}

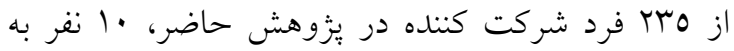
علت ياسخخويى ناقص به برسشنامها و ينج نقر به علت

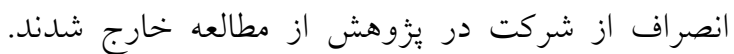
بنابراين، • • ب نفر نمونهاى نهايى اين يزوهش را تشكيل دادند كه از اين ميان، ال7 نفر (rVV/V) كاردان و 109 نفر

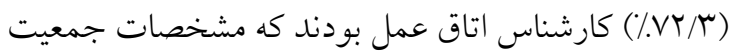

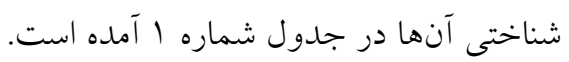

تجزيه و تحليل دادهها و به منظور گوياتر بودن نتايج حاصل از محاسبه نمرات، نمره كل برسشنامه از ل. إنمره محاسبه

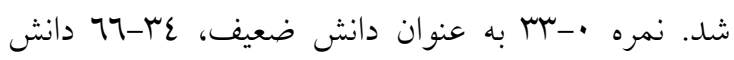
متوسط و TV- - . ابه عنوان دانش خوب در نظر كرفته شد.

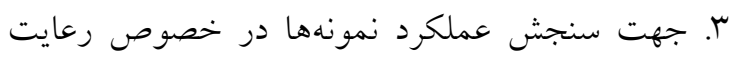

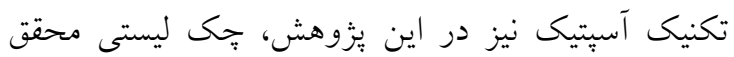

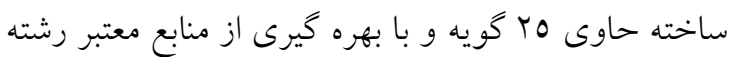

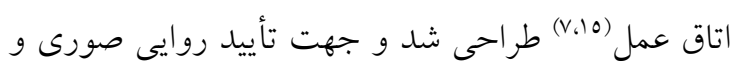
روايى محتوا در اختيار ·ل نفر از اساتيد هيئت علمى قرار

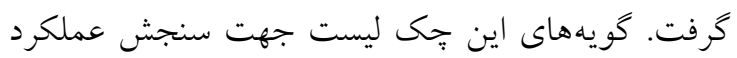
كاردانها و كارشناسان اتاق عمل هنگام اسكراب كردن، يوشيدن كان و دستكش استريل و حفظ استريليتى خود و

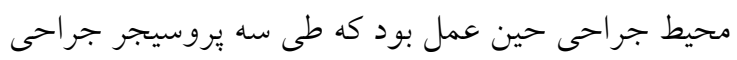

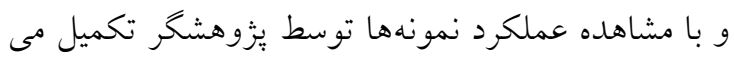

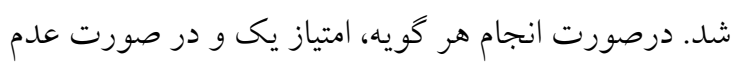

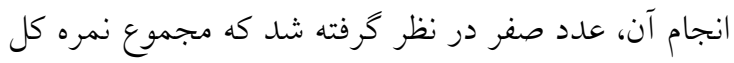

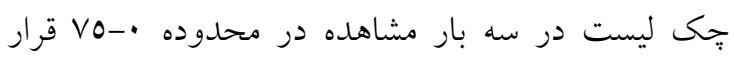

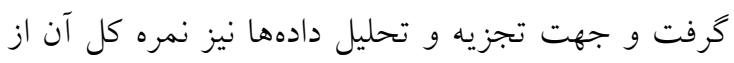

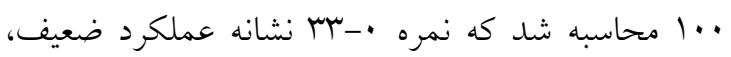

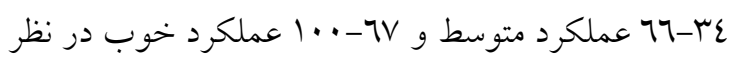
كرفته شد.

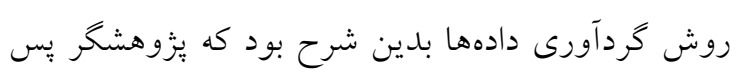

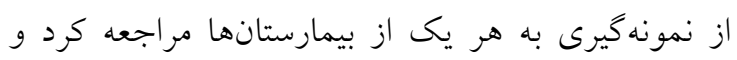

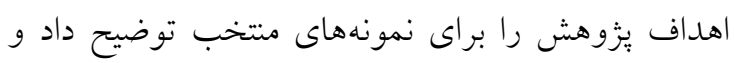

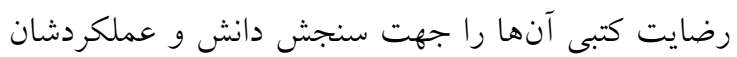

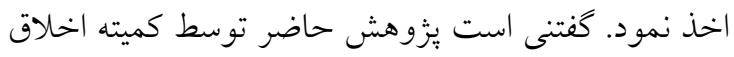

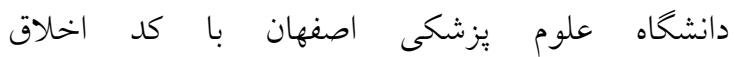
IR.MUI.REC.1396.1.209 مورد تأييد قرار گرفت. باه به نمونهها اطمينان داده شد كه نمرات حاصل از سنجش

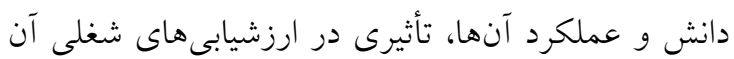

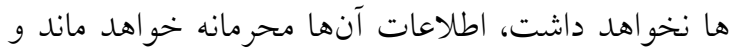

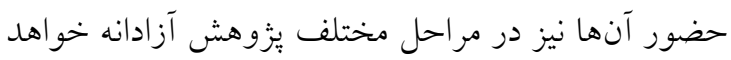




\begin{tabular}{|c|c|c|c|c|}
\hline \multirow[t]{2}{*}{ P-value } & \multirow[t]{2}{*}{ آزمون } & كارشناسان & كاردان ها & \multirow[t]{2}{*}{ متغير } \\
\hline & & تعداد= 109 & تعداد= 71 & \\
\hline \multirow[t]{2}{*}{$*<\cdot / \cdot \cdot 1$} & \multirow[t]{2}{*}{$\mathrm{T}=\Lambda / r V$} & \multirow[t]{2}{*}{$r \cdot / \tau(\tau / \varepsilon)$} & \multirow[t]{2}{*}{$\Gamma \wedge / 0(T / r)$} & سن (سال) \\
\hline & & & & ميانكين (انحر اف معيار) \\
\hline \multirow[t]{2}{*}{$*<\cdot / \cdot \cdot 1$} & \multirow[t]{2}{*}{$\mathrm{T}=\Lambda / \varepsilon q$} & \multirow[t]{2}{*}{$V / 0(7 / \varepsilon)$} & \multirow[t]{2}{*}{$10 / \Gamma(0 / \Gamma)$} & سابقه كار (سال) \\
\hline & & & & ميانكين (انحراف معيار) \\
\hline \multirow[t]{2}{*}{$* \cdot / \cdot r$} & \multirow[b]{2}{*}{$\chi^{2}=0 / \cdots 1$} & ITO (VN/7\%) & $r q(7 r / q \%)$ & جنسيت \\
\hline & & $r \varepsilon(r \mid / \varepsilon \%)$ & $r Y(r T / \%)$ & تعداد (درصد) \\
\hline
\end{tabular}

كارشناسان اتاق عمل در خصوص رعايت تكنيك آسيتيك

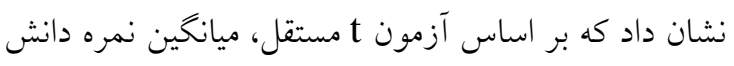

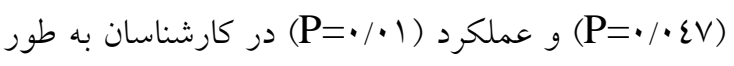

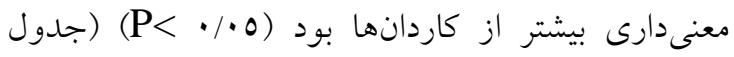

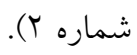
از آنجا كه بر اساس يافته هاى به دست آمده، متغيرهاى سن، جنسيت و سابقه كار در دو گروه تفاوت معنىدار

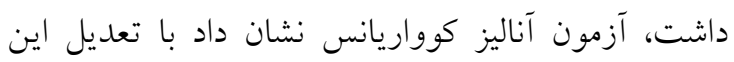

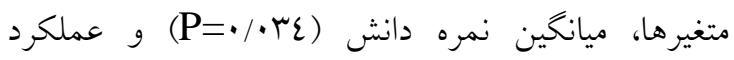

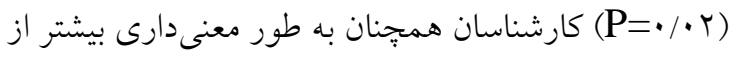

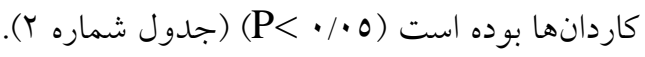

درخصوص مشخصات جمعيت شناختى دو گروه، آزمون t مستقل نشان داد كه ميانخين سن و سابقه كار در كاردان

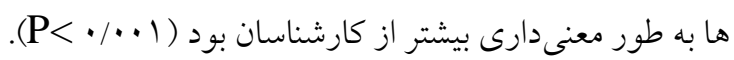

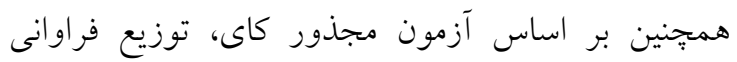

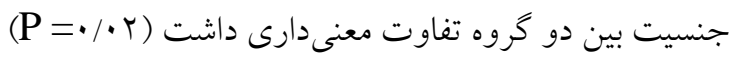

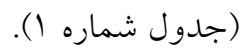

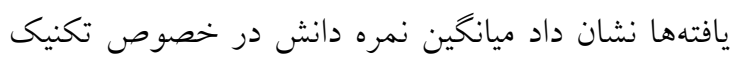

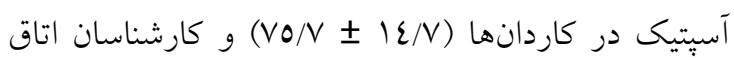

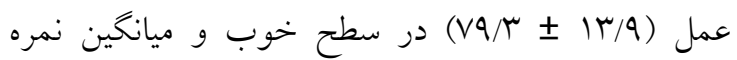

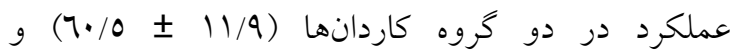

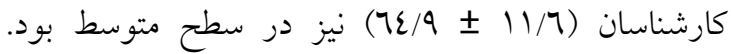
مقايسه ميانكين نمره دانش و عملكرد كاردانها و

جدول شماره ؟: ميانكَين نمره دانش و عملكرد در خصوص رعايت تكنيك آسبتيك در دو كَروه

\begin{tabular}{|c|c|c|c|c|c|c|}
\hline \multirow{2}{*}{ ANCOVA } & \multirow{2}{*}{ P-value } & \multicolumn{2}{|c|}{ كارشناسان } & \multicolumn{2}{|c|}{ كاردانها } & \multirow[b]{2}{*}{ نمره } \\
\hline & & انحر اف معيار & ميانخين & انحراف معيار & ميانخين & \\
\hline$* \cdot / \cdot r \varepsilon$ & $* \cdot / \cdot \varepsilon V$ & $1 \pi / 9$ & $\mathrm{~V} Q / \mu$ & $1 \varepsilon / V$ & Vo/V & دانش \\
\hline$* \cdot / \cdot r$ & $* \cdot 1 \cdot 1$ & $11 / 7$ & $7 \varepsilon / 9$ & $11 / 9$ & $7 \cdot 10$ & عملكرد \\
\hline
\end{tabular}

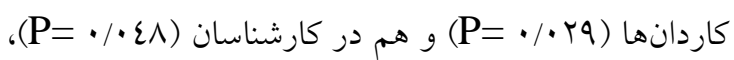

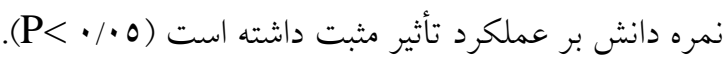
در خصوص ارتباط بين مشخصات جمعيت شناختى نمونه هاى دو گروه با نمره دانش و عملكرد آنها، بر اساس ضريب همبستخى بيرسون، در هيج يك از دو گروه بين نمره دانش و عملكرد درخصوص رعايت تكنيك آسيتيك با سن و سابقه كار و بر اساس آزمون t مستقل، بين نمره
ضريب همبستخى بيرسون نشان داد كه هم در كاردانها

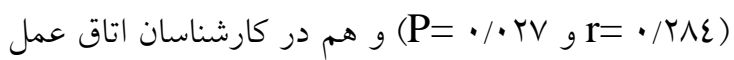

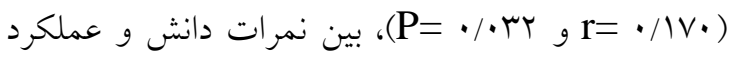
در خصوص رعايت تكنيك آستيكى رابطه مستقيم وجود داشت (P)

ضمناّ آناليز رگرسيون خطى جندگانه نيز نشان داد كه با تعديل متغيرهاى سن، جنسيت و سابقه كار نيز هم در 
دانش و عملكرد با جنسيت، ارتباط معنى دارى مشاهده نشد

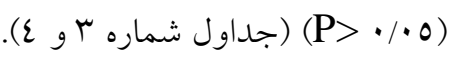

جدول شماره س: ضرايب همبستكى بيرسون بين نمره دانش و عملكرد در خصوص رعايت تكنيك آسيتيك با سن و سابقه كار در هر يك از دو تروه

\begin{tabular}{|c|c|c|c|c|c|}
\hline \multicolumn{2}{|c|}{ سابقه كار } & \multicolumn{2}{|c|}{ سن } & \multirow[t]{2}{*}{ نمره } & \multirow[t]{2}{*}{ كروه } \\
\hline P-value & $\mathbf{r}$ & P-value & $\mathbf{r}$ & & \\
\hline . $/ \Delta r$ & $-\cdot / \cdot \Delta F$ &.$/ 01$ & $-\cdot / \cdot 19$ & دانش & كاردانها \\
\hline . &.$/ \cdot 1 r$ &.$/ 9$. & .1 .19 & عملكرد & \\
\hline.$/ M A F$ & $.11 \cdot 9$ &.$/ 11$ & $\cdot / 1 \cdot v$ & دانش & كارشناسان \\
\hline$\cdot / \mathrm{VA}$ &.$/ \cdot r r$ &.$/ \Delta r$ & $\cdot / \cdot \Delta r$ & عملكرد & \\
\hline
\end{tabular}

جدول شماره ع: ميانكَين نمره دانش و عملكرد در خصوص رعايت تكنيك آسيتيك در هر يك از دو تروه به تفكيك جنسيت افراد مورد

\begin{tabular}{|c|c|c|c|c|c|c|c|}
\hline \multirow{2}{*}{ P-value } & \multirow{2}{*}{$\mathbf{t}$} & \multicolumn{2}{|c|}{ مرد } & \multicolumn{2}{|c|}{ زن } & \multirow[b]{2}{*}{ نمره } & \multirow[b]{2}{*}{ كروه } \\
\hline & & انحر اف معيار & ميانگين & انحر اف معيار & ميانخين & & \\
\hline$\cdot / 11$ & $\cdot / I V$ & $1 \pi / 1$ & VO/r & $10 / \varepsilon$ & $\mathrm{VO} / \mathrm{q}$ & دانش & كاردانها \\
\hline.$/ 17$ & $1 / \varepsilon r$ & $\mid r / 1$ & r & $11 / 1$ & $O N / \Lambda$ & عملكرد & \\
\hline$\cdot / \varepsilon r$ & $\cdot / \Lambda 1$ & $9 / 7$ & $\mathrm{VV} / \mathrm{T}$ & $1 \varepsilon / 1$ & Vq/V & دانش & كارشناسان \\
\hline$\cdot / 11$ & $1 / 9 \varepsilon$ & $1 \varepsilon / 0$ & $71 / 0$ & $1 \cdot / 7$ & $70 / 1$ & عملكرد & \\
\hline
\end{tabular}

اين مطالعه نيز از مراكز درمانى اصلى شهر اصفهان بودند كه تعداد مراجعات بيماران به آنها بالا بود و اين امر ممكن لئن نتايج يزوهش حاضر كه به منظور تعيين و مقايسهى دانش به است از عوامل تأثير گذار بر متوسط بودن سطح عملكرد و عملكرد كاردانها و كارشناسان اتاق عمل در خصوص يرستار ان اتاق عمل در اين مطالعه باشد. نتايج مطالعه حاضر

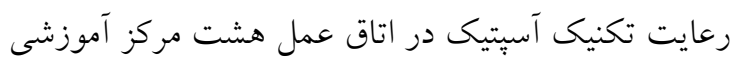
همراستا با مطالعه رستمى نزاد و همكاران مىباشد كه درمانى وابسته به دانشخاه علوم يزشكى اصفهان انجام شد، عملكرد كاركنان اتاق عمل بيمارستانهاى آموزشى شهر نشان داد كه نمره دانش كاردانها و كارشناسان اتاق عمل ياسوج در خصوص رعايت موازين كتترل عفونت را در در خصوص رعايت تكنيك آسيتيك در سطح خوب اما حد متوسط كزارش كردند(17). با اين حال در مطالعه نمره عملكرد آنها متوسط بود. اين نتايج را شايد بتوان اين Abraham كونه تفسير كرد كه با توجه به استرس شغلى، فشار كارى يرستاران اتاق عمل در خصوص تكنيك استريل در زياد، خستكى و فاصله زمانى كوتاه بين اعمال جراحى در بيمارستانى در جنوب هند، دانش در سطح خيلى خوب و عملكرد مناسب گزارش شد كه در اين مطالعه نيز از ״يرسشنامه و جָى ليستى محقق ساخته جهت سنجش دانش

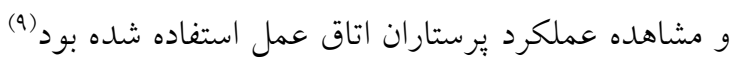
كه شايد از دلايل جنين نتايج متفاوتى، كمتر بودن حجم اتاق عمل و به ويزه در مراكز درمانى شلوغتر، كاركنان

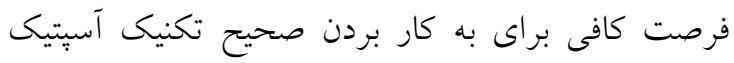

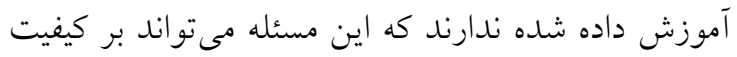

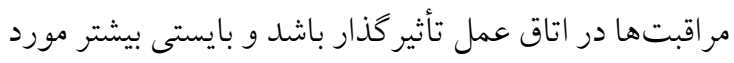

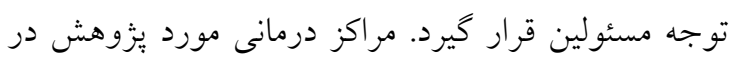


عمل در خصوص رعايت تكنيك آسيتيك يرداخته باشد به

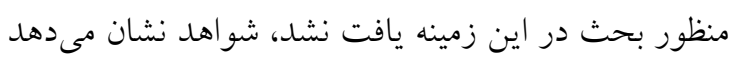

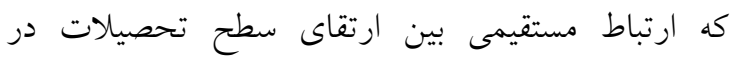

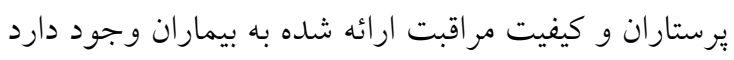

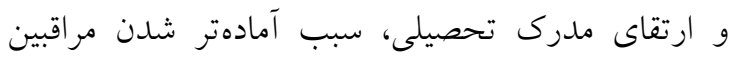

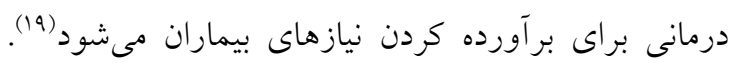

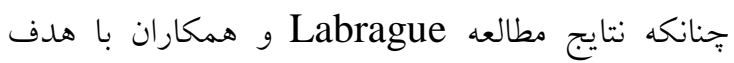
تعيين دانش و عملكرد يرستاران اتاق عمل در خصوص تكنيك استريل نيز نشان داد هر قدر دانش يرستاران بيشتر

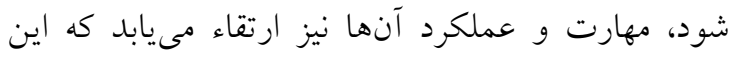
مسئله اهميت ادامه تحصيل در يرستاران اتاق عمل را به منظور رعايت تكنيك استريل و كاهش عفونتهاى بيمارستانى دو קندان مى كند (r). در مطالعه ديخرى توسط و و همكاران نيز مشخص شد دو يرستارانى كه سطح

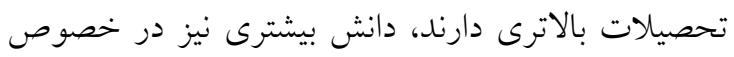

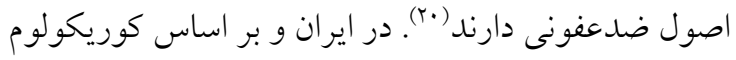

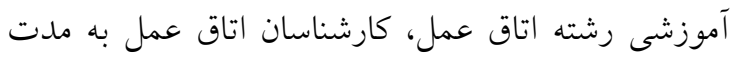

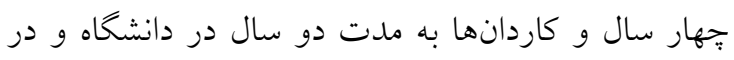

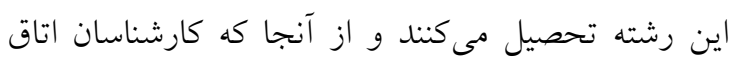
عمل تعداد واحدهاى درسى بيشترى را در زمينه رعايت

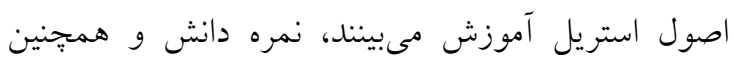

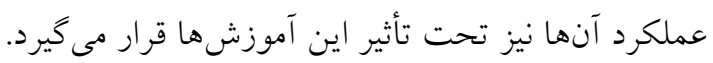
در اين بُزوهش اخرجه متغيرهاى سن، جنسيت و سابقه كار

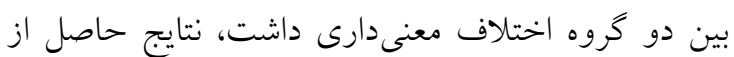
تعديل اين متغيرها نشان داد كه نمره دانش و عملكرد كارشناسان همجنان به طور معنى دارى بالاتر از كاردانها بوده است. بنابراين بالاتر بودن نمره دانش و عملكرد

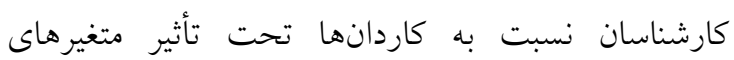
جمعيت شناختى آنها نبوده است. كاست كاردان در مطالعه حاضر اخرجهه نمره دانش دو گروه در سطح خوب و نمره عملكرد آنها متوسط بود، يافتهها نشان داد كه بين نمره دانش و عملكرد در خصوص تكنيك آسبتيك، ارتباط مستقيم وجود دارد. به كونهاى كه با افزايش نمره دانش، نمره عملكرد نيز در دو گروه ارتقاء يافته است. اين
نمونه در مطالعه Abraham و همكاران (ع7 نفر) در

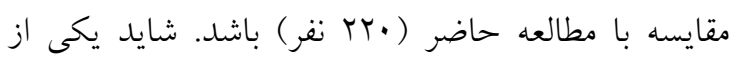

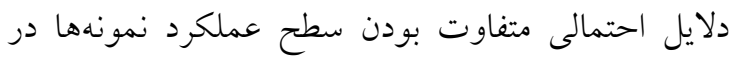
يزوهش Abraham و همكاران در مقايسه با مطالعه

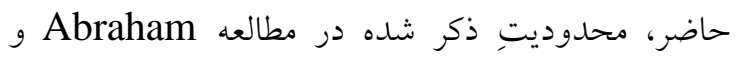

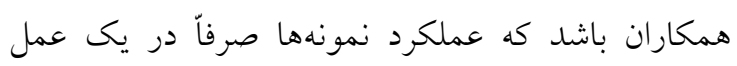
جراحى و فقط در يكى ساعت ابتدايى هر عمل مشاهده و ارزيابى شد و اين عملكرد به كل ساعات عمل تعميم داده شد، اما در مطالعه حاضر، عملكرد نمونهها طى سه يروسيجر جراحى و از ابتدا تا انتهاى عمل مورد مشاهده و ارزشيابى قرار كرفت. لذا احتمالاً نمره عملكرد بدست آمده تهري در مطالعه حاضر از دقت بيشترى برخوردار است.

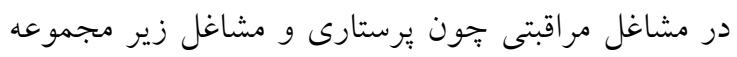

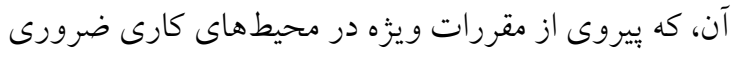

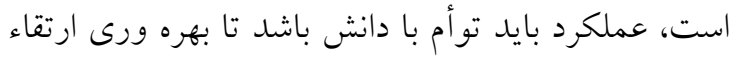

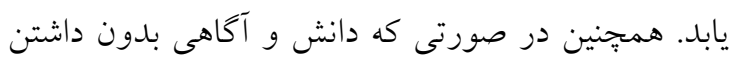

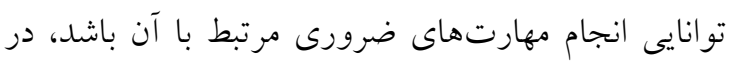

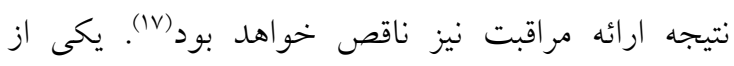

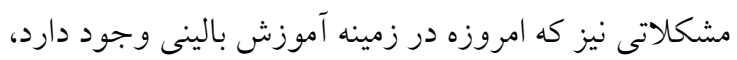

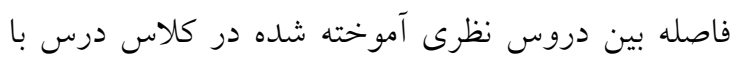

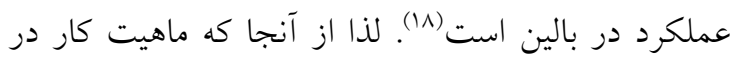

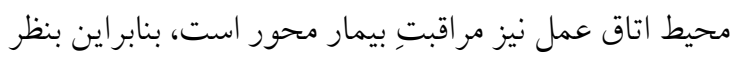

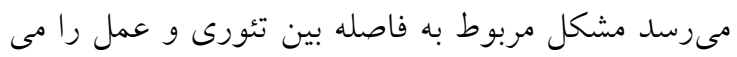

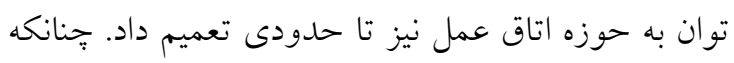
يافتهاى مطالعه حاضر نيز نشان داد، نمره دانش نمونهها در سطح خوب و نمره عملكرد آنها متوسط بود و نمره دانش و عملكرد با يكديخر همسطح نبود كه يكى از دلايل احتمالى آن مى تواند همين امر باشد.

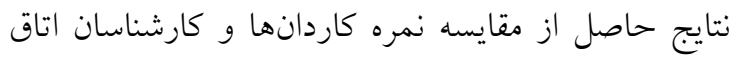
عمل در خصوص رعايت تكنيك آسيتيك نشان داد كه ميانخين نمره دانش و عملكرد كارشناسان اتاق عمل به طور معنى دارى بيشتر از كاردانها بود. اخر جهه در جستجوهاى

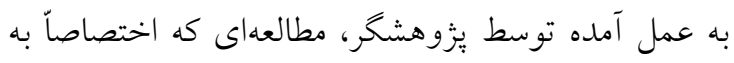

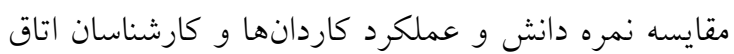


تكنيك آسيتيك در سطح خوب و عملكرد آنها متوسط بود. همجنين دانش و عملكرد كارشناسان، بالاتر از كاردان ها بود. عفونت محل جراحى يكى از عوارض شايع پِ از عمل است كه رعايت تكنيك آسيتيك مىتواند يكى از راه هاى بيشخيرى از بروز آن باشد. بنابراين اقداماتى جهون

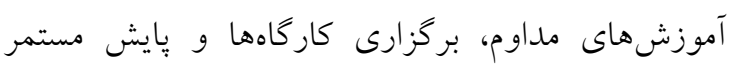
دانش و عملكرد كاركنان، بر بهبود عملكرد آنها نقش مؤثرى دارد. بنابراين اميد مىرود يافتههاى اين يزوهش، زمينه ساز اعمال نظارت دقيقتر بر عملكرد مراقبين درمانى، ايجاد فرصت براى تبديل دانش آموخته شده به عمل در بالين و همخام كردن دانش با عملكرد شوند و كاركنان نيز نسبت به ارتقاى سطح تحصيلات و ادامه تحصيل تشويق شوند.

تعارض منافع: هيجگُ نه تعارض منافع توسط نويسند گان بيان نشده است.

\section{تقلدير و تشكر}

اين مقاله بركرفته از طرح تحقيقاتى به شماره 9 •.197r با حمايت مالى كميته تحقيقات دانشجويى دانشخاه علوم يزشكى اصفهان مىباشد. بدين وسيله از كاركنان اين مركز و تمامى كاركنان اتاق عمل بيمارستانهاى مورد بِّوهش كه با همكارى خود، زمينه را براى انجام اين مطالعه فراهم

$$
\text { نمودند، قدردانى مى گردد. }
$$

امر حاكى از آن است كه ميزان دانش و آكاهى نسبت به تكنيك آسيتيك، مىتواند بر عملكرد نيز تأثير كذار باشد. با لـا اين حال همان طور كه بيشتر ذكر شد، يكى از مشكلات آموزش بالينى در رشتههاى يرستارى و حرفههاى زير مجموعه آن، فاصله بين تئورى با عملكرد است (1). در همين راستا، يافتههاى مطالعه Kolade و همكاران كه با ليا هدف بررسى دانش، نخرش و عملكرد بِرستاران در خصوص بيشخيرى از SSI انجام شد نيز نشان داد كه بين دانش و عملكرد نمونهها ارتباط مستقيم وجود داشت (ع). در اين يزوهش همجنين بين نمره دانش و عملكرد با مشخصات جمعيت شناختى نمونهها ارتباط معنىدارى يافت نشد، اگر جهه انتظار مىرفت كه افراد با سابقه كارى بيشتر، دانش و عملكرد بهترى نيز داشته باشند. بنابراين احتمال مىرود كه نمره دانش و عملكرد نمونهها تحت تأثير عوامل ديخرى باشد كه بيشنهاد مىشود در يزّوهشهاى آينده اين عوامل مورد بررسى قرار كيرند. اين نتايج مشابه

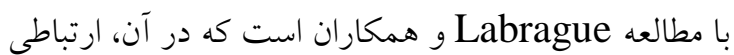
بين دانش و عملكرد يُ ستاران اتاق عمل با سن، جنسيت و

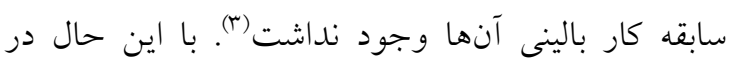

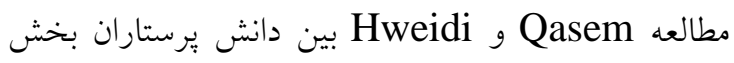
مراقبتهاى ويزه در خصوص بيشخيرى از عفونت محل عمل با سن و سابقه كارى آنها رابطه معنى دارى به دست آمد

در مجموع نتايج اين مطالعه حاكى از آن است كه دانش كاردانها و كارشناسان اتاق عمل در خصوص رعايت

\section{References}

1. Sonoda Y, Onozuka D, Hagihara A. Factors related to teamwork performance and stress of operating room nurses. Journal of nursing management. 2018;26(1):66-73.

2. Zarei MR, Tabesh H, Fazeli H, Aarabi A. The effect of incise drape on the incidence of surgical site infection following lumbar spine surgeries. J Isfahan Med Sch. 2018;36 (498):1165-74. [Persian]

3. Labrague LJ, Arteche DL, Yboa BC, Pacolor NF. Operating room nurses' knowledge and practice of sterile technique. J Nurs Care. 2012;1(4):1-5.

4. Nakhaee M, Alinejad MS. Investigating Nurses'knowledge and Self-Efficacy Regarding the Principles of Infection Control in the Operating Room. MODERN CARE JOURNAL. 2015;12(2):79-83. [Persian]

5. Qasem MN, Hweidi IM. Jordanian nurses' knowledge of preventing surgical site infections in acute care settings. Open J Nurs. 2017;7(05):561-82. 
6. Smith MA, Dahlen NR, Bruemmer A, Davis S, Heishman C. Clinical practice guideline surgical site infection prevention. Orthopaedic Nursing. 2013;32(5):242-8.

7. Phillips N. Berry \& Kohn's operating room technique. Elsevier Health Sciences; 2016 Mar 4.

8. Spruce L. Back to basics: speak up. AORN Journal. 2014;99(3):407-15.

9. Abraham SP, Deva R, Babu V. The knowledge and practice of operating room nurses regarding sterile technique in a tertiary hospital. South India. 2016;5(3):63-6.

10. Singh N, Rani M, Kumari P. Assessment of Knowledge of Staff Nurses Regarding Aseptic Techniques at Selected Hospital-A Descriptive Survey Study. Int J Health Sci Res. 2016;6(9):2904.

11. Hopper WR, Moss R. Common breaks in sterile technique: clinical perspectives and perioperative implications. AORN Journal. 2010;91(3):350-67.

12. Eskander HG, Morsy WY, Elfeky HA. Intensive care nurses knowledge \& practices regarding infection control standard precautions at a selected Egyptian Cancer Hospital. prevention. 2013;4(19):160-74.

13. Ghadmgahi F, Zighaimat F, Ebadi A, Houshmand A. Knowledge, attitude and self-efficacy of nursing staffs in hospital infections control. Journal Mil Med. 2011;13(3):167-72. [Persian]

14. Kolade OA, Abubakar S, Adejumoke SR, Funmilayo HV, Tijani A. Knowledge, attitude and practice of surgical site infection prevention among post-operative nurses in a tertiary health institution in north-central Nigeria. International Journal of Nursing and Midwifery. 2017;9(6):659.

15. Rothrock JC. Alexander's Care of the Patient in Surgery-E-Book. Elsevier Health Sciences; 2018 Jan 16.

16. Rostaminejad A, Mobaraki A, Zahmatkeshan N. Performance of the operating room personnel in following of the standards of infection control in the educational hospitals of Yasuj University of Medical Sciences in 2009. Armaghane Danesh. 2011;16(1):90-9. [Persian]

17. Salmani Mud M, Memarian R, Vanaki Z. Effect of implementation staff development program based on evidences for supervisors on nurses, practice. Quarterly Journal of Nursing Management. 2012;1(3):9-18. [Persian]

18. Shawish FA, UY PP, Payagen LT, Kiblasan JI, Elwahaishi SS. Comparative Study on Compliance to Standard of Preoperative Surgical Asepsis among Scrub Nurses in Misurata, Libya. International Journal of Nursing Science. 2015;5(3):93-6.

19. Battié RN. Perioperative nursing and education: what the IOM Future of Nursing report tells us. AORN Journal. 2013 Sep 1;98(3):249-59.

20. Sessa A, Di Giuseppe G, Albano L, Angelillo IF. An investigation of nurses' knowledge, attitudes, and practices regarding disinfection procedures in Italy. BMC Infect Dis. 2011;11(1):14. 